\title{
PROBLEMATIKA PENDIDIKAN AGAMA ISLAM DI LEMBAGA PENDIDIKAN DAN PENGEMBANGAN PROFESI INDONESIA (LP3I) BUSINESS COLLEGE MALANG
}

\author{
Sudirman \\ Fakultas Ilmu Tarbiyah dan Keguruan \\ Universitas Islam Negeri Maulana Malik Ibrahim Malang \\ Email: dirmannahrawi70@gmail.com
}

\begin{abstract}
The needs of Islamic education in universities is very high, meaning that students are very important for religious education is provided mainly in the field of belief and morals. The Lecturer of Islamic religion in LP3I-Business College e Unfortunate problem encountered is a lot to know about the science of business science and the world of work to mengkolaborasi with Islamic religious education courses (PAI). Lecturer of Islam that teaches Islamic education (PAI) in LP3I-Business College to take steps in teaching PAI, namely: 1. Choose the mosque as a place of teaching and learning from on set in the classroom as the other courses. 2. Require the student to establish the prayer dhuha and recite the Qur'an (verses) before the course begins. 3. Divide the group class discussion in accordance with the material PAI (Islamic education) in LP3I Business College syllabus hapless then presented by the method of discussion in order to make students more easily understand the religious values of Islam especially problem beliefs and morals. 4. Hold the oral exam (reading Quran) and the practice of the prayer at the end of the meeting, in addition there are middle test and final test, the goal to be more intensive.
\end{abstract}

Key Words: Islamic Education, LP3I, Business College

\begin{abstract}
Abstrak: Kebutuhan pendidikan agama Islam di Perguruan tinggi sangat tinggi, artinya anak didik sangat penting untuk dibekali pendidikan agama terutama di bidang akidah dan akhlak. Mereka sangat membutuhkan nasehat nasehat agama. Dosen agama Islam di LP3I Business College Malang problem yang dihadapi adalah harus banyak tahu tentang ilmu ilmu bisnis dan dunia kerja untuk mengkolaborasi dengan mata kuliah pendidikan agama Islam (PAI). Dosen agama Islam yang mengajarkan Pendidikan Agama Islam (PAI) di LP3I-Business College Malang mengambil langkah- langkah dalam mengajarkan PAI, yaitu: 1. Memilih masjid sebagai tempat PBM ( proses belajar mengajar) dari pada bertempat di dalam kelas sebagaimana mata kuliah yang lain. 2. Mewajibkan mahasiswa untuk mendirikan shalat dluha dan mengaji al Qur'an (beberapa ayat) sebelum mata kuliah dimulai. 3. Membagi kelompok diskusi kelas sesuai dengan materi PAI (Pendidikan Agama Islam) di silabus LP3I-Business College Malang yang kemudian dipresentasikan dengan metode diskusi agar mahasiswa lebih mudah dalam memahami nilai-nilai agama Islam terutama masalah akidah dan akhlak. 4. Mengadakan ujian lisan (tilawatil Qur'an) dan praktek shalat di penghujung pertemuan, selain ada UTS dan UAS, tujuannya agar lebih intensive.
\end{abstract}

Kata-Kata Kunci: Pendidikan Agama Islam, LP3I, Business College 


\section{Pendahuluan}

Kebutuhan pendidikan agama Islam di Perguruan tinggi umum sangat tinggi, artinya anak didik sangat penting untuk dibekali pendidikan agama terutama di bidang akidah dan akhlak. Mereka sangat membutuhkan nasehat nasehat agama. Namun terdapat beberapa problematika, di antaranya tidak semua peserta didik yaitu mahasiswa terbiasa shalat dengan benar, kurang terbiasa membaca al Qur'an dengan baik, sehingga pendidikan agama Islam sedikit agak kurang lancar. Sedangkan bagi dosen agama Islam di LP3I Business College Malang problem yang dihadapi adalah harus banyak tahu tentang ilmu ilmu bisnis dan dunia kerja untuk mengkolaborasi dengan mata kuliah pendidikan agama Islam (PAI).

Seorang muslim yang bertaqwa, bukan hanya menghindari semua hal yang dilarang, bahkan lebih dari itu dia hendaknya menghindari wilayah kelabu (Shubḥāt). Apabila ia melakukan tindakan itu ia merasa tidak mendapatkan ketentraman batin. Singkatnya, perilaku seseorang hendaknya diwarnai oleh suatu tindakan dan niat yang tulus sesuai dengan kadar dirinya sebagai makhluk Allah yang mulia. Allah telah meniupkan ruh pada salah satu di antaranya, sebagaimana dalam firman Allah (Shād (38) : 72):

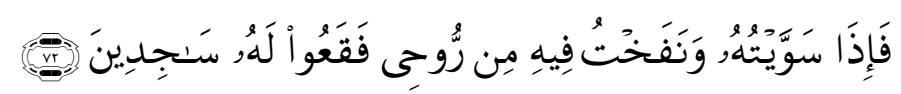

Maka apabila telah Aku sempurnakan kejadiannya dan Aku tiupkan kepadanya ruh (ciptaan)-Ku; maka hendaklah kamu tersungkur dengan bersujud kepadaNya" (Mujamma', 1968, 741).

Perkembangan kehidupan modern dengan segala nilai-nilai yang ditimbulkannya ternyata telah menimbulkan dampak negatif di samping dampak positif yang berujung pada krisis mental dan moralitas umat manusia, tak terkecuali bangsa Indonesia, khususnya mahasiswa-mahasiswa di perguruan tinggi umum, yang dalam hal ini di kampus Lembaga Pendidikan dan Pengembangan Profesi Indonesia (LP3I) Business College Malang. Kondisi semacam ini semakin mempertegas betapa pentingnya pendidikan agama Islam yaitu pembinaan akhlak secara Islami (akhlāq al karīmah), khususnya dalam berprilaku dalam sosial kemasyarakatan.

Salah satu yang membedakan Islam dengan non Islam adalah bahwa Islam tidak pernah memisahkan antara pendidikan dengan etika, sebagaimana juga tidak memisahkan ilmu dengan akhlak, politik 
dengan etika, ekonomi dengan etika, perang dengan etika dan kerabat sedarah sedaging dengan kehidupan Islam. Islam adalah risalah yang diturunkan Allah melalui Rasul untuk membenahi akhlak manusia. Nabi Muhammad Saw bersabda:

$$
\text { إنما بعثتُ لأتمّم مكارم الأخلاق رواه إمام بخاري }
$$

Sesungguhnya aku diutus untuk menyempurnakan akhlak mulia.(Hadits riwayat Imam Bukhari) (Al-Bukhārī, 2011; Sudirman, 2014, 165).

Islam juga tidak memisahkan agama dengan negara dan materi dengan spiritual sebagaimana yang dilakukan Eropa dengan konsep sekularismenya. Islam juga berbeda dengan konsep kapitalisme yang memisahkan akhlak dengan ekonomi. Disamping akhlak dikenal pula istilah moral dan etika. Moral berasal dari bahasa latin mores yang berarti adat kebiasaan. Moral selalu dikaitkan dengan ajaran baik buruk yang diterima umum atau masyarakat. Karena itu adat istiadat masyarakat menjadi standar dalam menentukan baik dan buruknya suatu perbuatan. Etika adalah sebuah tatanan prilaku berdasarkan suatu sistem tata nilai suatu masyarakat tertentu, etika lebih banyak dikaitkan dengan ilmu atau filsafat, karena itu yang menjadi standar baik dan buruk itu adalah akal manusia. Jika dibandingkan dengan moral, maka etika lebih bersifat teoritis sedangkan moral bersifat praktis. Moral bersfat lokal atau khusus dan etika bersifat umum. Perbedaan antara akhlak dengan moral dan etika dapat dilihat dari dasar penentuan atau standar ukuran baik dan buruk yang digunakannya. Standar baik dan buruk akhlak berdasarkan al Qur'an dan al sunnah, sedangkan moral dan etika berdasarkan adat istiadat atau kesepakatan yang dibuat oleh suatu masyarakat. Jika masyarakat menganggap suatu perbuatan itu baik, maka baik pulalah nilai perbuatan itu. Dengan demikian standar nilai moral dan etika bersifat lokal dan temporal, sedangkan standar akhlak bersifat universal dan abadi (Tim Direktorat PTAI, 2001, 167-168). Muslim, individu maupun kelompok dalam lapangan ekonomi, satu sisi diberi kebebasan untuk mencari keuntungan sebesar-besarnya. Namun disisi lain, ia terikat dengan iman dan etika sehingga ia tidak bebas mutlak dalam menginvestasikan modalnya atau membelanjakan hartanya. Masyarakat muslim tidak bebas tanpa kendali dalam memproduksi segala sumber daya alam, mendistribusikannya atau mengkonsumsinya, ia terikat dengan buhul aqidah dan etika mulia, disamping juga dengan hukum-hukum Islam (Al-Qarḍāwī, 2000, 51). 
Di Lembaga Pendidikan dan Pengembangan Profesi Indonesia (LP3I) Business College Malang kaitannya dengan dunia bisnis, menurut 'Abd Al Karīm Al-Khāțib (1976, 151-152) dalam rangka menghapus semua bentuk kejahatan dalam bisnis, Islam berusaha membendung dan menutup semua saluran yang mengarah kepada perilaku ketidakadilan, seperti minuman keras dengan kadar yang sedikit bisa saja tidak memabukkan, namun hal itu dilarang, karena yang sedikit itu akan mendorong seseorang untuk mengkonsumsi kadar yang lebih besar yang pasti memabukkan.. Tujuan utama dari ajaran Islam dalam masalah ekonomi dan bisnis (perdagangan) adalah untuk menjamin hak hak individu dan menjaga solidaritas sosial untuk mengenalkan nilai moralitas yang tinggi dalam dunia bisnis dan untuk menerapkan hukum Allah dalam dunia bisnis (Hammudah, 1976, 128). Menurut Yusūf al Qarḍāwī $(1997,201)$ diantara bidang yang terpenting dalam perekonomian adalah bidang distribusi, sehingga sebagian dosen agama Islam di LP3I Business College Malang mengaitkan dengan ekonomi Islam memusatkan perhatiannya kepada bsnis syari'ah. Mahasiswa dan mahasiswi LP3I Business College Malang difokuskan pada dunia kerja yang professional. Dengan demikian Pendidikan agama Islam banyak menyinggung dunia kerja dan ekonomi Islam yang bebas dari tindak kapitalis dan sosialis. Islam menerapkan filsafat dan tatanan yang berbeda dari kedua system tersebut. Islam memfokuskan perhatiannya pada distribusi sebelum membahas sektor produksi, hal ini tidak berarti Islam tidak memperhatikan keuntungan yang diperoleh dari produksi. Islam memberikan gaji secara adil kepada para pegawai dan buruh jika mereka melaksanakan tugas dengan sempurna, sebagaimana Islam dengan tegas menolak segala bentuk riba. Baru-baru ini, para ekonom juga mengakui bahaya bunga dalam aktivitas ekonomi. Distribusi ekonomi Islam berdiri diatas dua sendi, yaitu sendi kebebasan dan sendi keadilan (Yusūf al-Qarḍāwī, 1997, 203).

Allah Swt berfirman (Adz-Dzariyat (51) : 19);

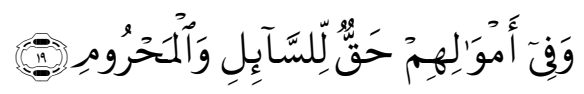

Dan pada harta-harta mereka ada hak untuk orang miskin yang meminta dan orang miskin yang tidak mendapat bagian.

Arti penting kekayaan memerlukan keberadaan dan wujudnya, minimal mampu memuaskan kebutuhan dasar semua anggota masyarakat. Penyediaan makanan dalam level minimum pada manusia 
ini oleh Al-Qur'an dianggap sebagai kewajiban masyarakat dan Negara. Dengan kata lain, tersedianya kebutuhan dasar adalah hak setiap individu tanpa harus melihat ras warna kulit, agama,jenis kelamin, usia, kesehatan serta status tiap individu.

Sistem Al-Qur'an dalam distribusi kekayaan ini didasarkan pada anjuran infaq, yang akan memberikan garansi bagi tersebarnya secara meluas distribusi kekayaan. Sistem ini adalah sebuah antitesa dari praktekpraktek riba, dimana dalam praktek ini, kekayaan terkumpul pada satu tangan, dan pada saat yang bersamaan terdapat perlakuan eksploitatif terhadap masyarakat yang kurang mampu. Dua konsep ini sangat bertolak belakang secara mendasar, tujuan dan konsekwensinya. Ilustrasi paling baik tentang adanya pertentangan antara dua konsep ini, bisa dilihat dalam Surat Ali Imran ayat 3, dimana orang-orang yang bertaqwa, dioposisikan dengan orang-orang yang melakukan riba dengan dasar bahwasanya; Pertama; Orang-orang yang beriman, membelanjakan harta kekayaannya demi kepentingan orang lain. Sedangkan yang Kedua; Para pemakan riba, mereka menggerogoti secara tidak adil kekayaan orang lain (Qutb, 1967, 52-53). Menurut Babili $(1975,126)$ Riba bukan hanya dikutuk, namun ia dilarang karena ia merupakan factor utama timbulnya konsentrasi kekayaan, sebagaimana Riibalah yang akan membidani lahirnya rasa Thama' dan bakhil / kikir.

Menurut S. M. Yusūf $(1971,57)$, bahwasanya "Menyimpan harta (saving) dengan cara mengingkari penggunaan dalam kenikmatan yang wajar akan menghancurkan proses distribusi dan menutup roda pembangunan".

Dalam Al-Qur'an (Al-Hasyr (59) ayat 9):

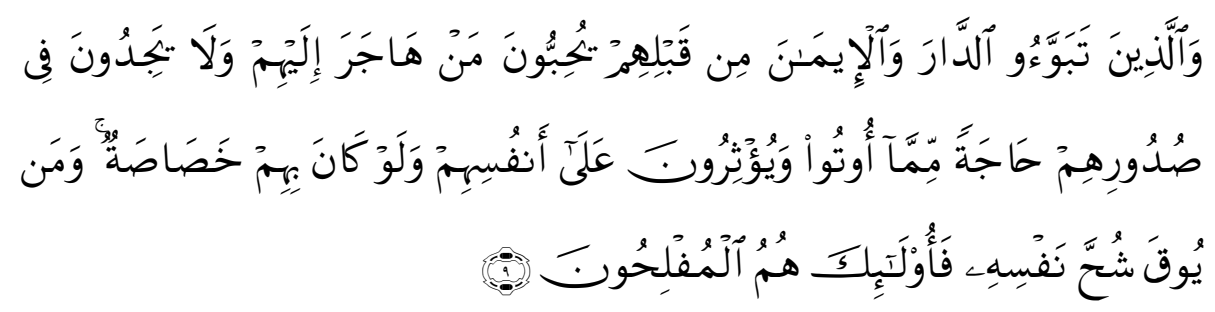

Dan orang-orang yang telah menempati kota Madinah dan telah beriman (Anshor) sebelum (kedatangan) mereka (Muhajirin), mereka (Anshor) 'mencintai' orang yang berhijrah kepada mereka (Muhajirin). dan mereka (Anshor) tiada menaruh keinginan dalam hati mereka terhadap apaapa yang diberikan kepada mereka (Muhajirin); dan mereka mengutamakan (orang-orang muhajirin), atas diri mereka sendiri, Sekalipun mereka dalam kesusahan. dan siapa yang 
dipelihara dari kekikiran dirinya, mereka Itulah orang orang yang beruntung.

Yang menurut At-Thahawi $(1974,214)$ dalam ayat ini perintah Al-Qur'an tentang infaq ini demikian keras dan sekaligus persuasive, Seorang mu'min diserukan untuk memberi infaq kepada orang lain tanpa menghiraukan kepentingan pribadinya. Prilaku yang sangat dermawan (itsaar) dari pada sahabat ini telah Al-Qur'an rekam, tak kurang dari 11 ayat dalam Al-Qur'an yang menyuruh kaum Mu'minin untuk mengorbankan harta dan jiwanya dijalan Allah SWT. (At-Thahawi, 1974, 214).

Saat membahas Ajaran Al-Qur'an tentang infaq, Maududi (1969, 115) menarik suatu konklusi bahwasanya kekayaan itu jangan sampai ditahan karena bakhil / kikir dan jangan pula digunakan atau di tasarrufkan pada jalan yang bathil, Sebaliknya harta itu harus selalu beredar dengan sirkulasi yang konstan sehingga manusia dapat mengambilo keuntungan dari sirkulasi harta itu (Maududi, 1969, 115).

Seseorang menurut Mufti Shafi' (1968, 14) hendaknya menafkahkan hartanya dijalan yang akan mengantarkan dirinya pada kebahagiaan dihari akhir dan juga demi memberikan kebahagiaan pada orang-orang fuqara' wal masakin wal mustadl'afin (faqir miskin yang lemah).

Rasulullah SAW menyatakan bahwa "Seluruh manusia adalah satu "Keluarga" Allah, dan manusia yang paling dekat kepada Allah SWT adalah orang yang paling baik terhadap "family"- Nya." (Hussain, 1974, 38; Babilli, 1975, 103). Al-Qur'an menegaskan bahwa menafkahkan harta dijalan Allah SWT, berarti seseorang telah membangun hubungan dengan Allah SWT dalam bisnis mereka, dan pahalanya akan berlipat ganda (Rahman, 1974, 40). Al-Qur'an juga tidak memberikan lisensi bebas untuk mendapatkan harta kekayaan dengan segala cara (Muhajir, 1974, 150).

Dosen agama Islam dalam mengajarkan pendidikan agama Islam di LP3I Malang ini mengaitkan dengan ilmu ekonomi dibidang distribusi. Menurut Adiwarman A. Karim $(2011,242)$ distribusi dan alokasi sumberdaya dalam ekonomi Islam sangat jelas dan penanganan masalah dapat dilakukan dengan teknik ekonomi dengan keuntungan maksimum. Menurut Ilfi Nur Diana $(2011,61)$, distribusi pendapatan (baca: kekayaan) adalah suatu proses pembagian (sebagian hasil penjualan produk total) kepada faktor-faktor yang ikut menentukan pendapatan, yakni tanah, tenaga kerja, modal, dan manajemen. 
Dosen agama Islam di LP3I Business College Malang dituntut untuk bisa menjabarkan pendidikan agama Islam (PAI) dengan dunia bisnis yang erat kaitannya dengan dunia ekonomi dan dunia kerja sehingga kerjanya dua kali lipat dari pada dosen agama di perguruan tinggi umum lainnya. Dan hendaknya dosen agama di LP3I Business College Malang harus dapat membangun karakter mahasiswa muslim, sehingga pembelajaran pendidikan agama Islam mudah dan dapat diterima.

Dari hasil penelitian pendidikan agama Islam di Lembaga Pendidikan dan Pengembangan Profesi Indonesia (LP3I) Business College Malang ini dapat di simpulkan: Dosen agama Islam yang mengajarkan Pendidikan Agama Islam (PAI) di LP3I-Business College Malang mengambil langkah- langkah dalam mengajarkan PAI, yaitu: 1 . Memilih masjid sebagai tempat PBM ( proses belajar mengajar) dari pada bertempat di dalam kelas sebagaimana mata kuliah yang lain. Tujuannya membiasakan mahasiswa mengenal dan mencintai masjid, beri'tikaf dan menjadi mudah dalam praktek sholat dan praktek membaca al Qur'an al Karim. 2. Mewajibkan mahasiswa untuk mendirikan shalat dluha dan mengaji al Qur'an (beberapa ayat) sebelum mata kuliah dimulai. 3. Membagi kelompok diskusi kelas sesuai dengan materi PAI (Pendidikan Agama Islam) di silabus LP3IBusiness College Malang, yang kemudian dipresentasikan di depan, dengan metode diskusi ini diharapkan mahasiswa-mahasiswi lebih mudah dalam memahami nilai-nilai agama Islam terutama masalah akidah dan akhlak. 4. Mengadakan ujian lisan (tilawatil Qur'an) dan praktek shalat (Wajib menghafal bacaan -bacaan yang dibaca dalam shalat dan maknanya) di penghujung pertemuan, selain ada UTS dan UAS, tujuannya agar lebih intensive. 


\section{Daftar Pustaka}

'Abdal 'Ati, Hammudah, (1976). Islam In Focus. Indianapolis; American Trust Publication.

'Abdul Karīm Al-Khāțib, (1976). As-Siyāsah Al-Maliyyah fi Al-Islām wa șilatuhu bi al-Mu'amalāt al-Mu'āṣirah. Cairo; Dār al-Fikr al-'Arabi.

'Alī, 'Abdullah Yūsuf, (1968). The Holy Qur'an: Text.Translation and Commentary, Beirut; Dār At Tibā'ah wa Al Nashr wa At Tawzī.

Abī 'Abd Allah Muḥammad bin Ismā’îl bin Ibrāhīm Ibn Al-Mughīrah bin Bardazabah Al-Bukhārī Al-Ja'fī, (2011). Al-Adāb al-Mufrad", Lebanon: Dār al-Kutub Al-Ilmiyah.

Adiwarman A.Karim, (2011). Ekonomi Mikro Islam. Jakarta; PT.Raja Grafindo Persada.

Al-Qardlawi, Yusuf, (1997). Daur al Qiyaam wa al Akhlaaq fii al Iqtishaadi al Islaami. Cairo: Maktabah Wahbah.

At-Thahawi, Ibrahim, (1974). Al-Iqtishad Al-Islami. V.1. Cairo: Majma' AlBuhuts Al-Islamiyyah.

Babilli, Mahmud Muhammad, (1975). Al-Maal fii Al-Islaam, Beirut; Daar Al-Kitab Al Lubnani.

Babilli, Mahmud Muhammad, (1975). Al-Maal fii Al-Islaam, Beirut; Daar Al-Kitab Al Lubnani.

Hussain, Muzaffar, (1974). Motivation for Ekonomic Achievement In Islam, Lahore, All Pakistan Islamic Education Conggres.

Ilfi Nur Diana, (2011). Hadits-hadits Ekonomi. Malang; UIN Maliki Press.

Maududi, Sayyid Abu Al-A'la, (1969). Mu'asyiyat Islam, Lahore; Islamic Publication.

Muhajir, Ali Musa Razi, (1974). Islam in Practical Life, Lahore; Sh. Muhammad Ashraf 
Mujamma' Al-Malik Fahd Li thibā'āt al-Muṣhaf al-Sharīf Madīnah Munawwarah, (tt.). Al-Qur'ān Al-Karìm Watarjamatuhu Ilallughah Al-Indonesiyyah, Kerajaan Saudi Arabia.

Qutb, Sayyid, (1967). Fii Zhilaal Al-Qur'an, 5 th ed. Beirut; Daar Ihya at Thurats Al-'Arabi.

Rahman, Fazlur, (1974). Economic Doctrines of Islam, 3. Vols, Lahore; Islamic Publication.

Shafi', Mufti Muhammad, (1968). Islam Ka Nizham-I Taqsim-I Dawlat, Karachi: Maktabah Daar Al-'Ulum.

Sudirman, (2014). Fiqh Studies (sesuai prodi IPS). Malang: Dream Litera Buana.

Tim Direktorat PTAI, ( 2001). Buku Teks: Pendidikan Agama Islam Pada Perguruan Tinggi Umum, Jakarrta: DirJend. Kelembagaan Agama Islam Departemen Agama RI.

Yūsuf Al-Qarḍāwī, (2000). Daur al Qiyām Wal Akhlāq Fï al Iqtișādi al Islāmī (Norma dan Etika Islam), Jakarta: GIP.

Yusuf, S, M, (1975). Ekonomic Justice in Islam, Lahore; Sh. Muhammad Asyraf. 